\title{
Teacher Job Satisfaction in High-Performing Systems: \\ A Multi-Level Study of Teacher, Classroom, and School Factors Using TALIS 2013 Surveys
} Asia Pacific Journal of Educational Research 2020. Vol. 3(1) 17-43

(c) The Author(s) 2020

\section{Yipeng Tang}

East China Normal University, China

\section{Ting Wang}

University of Canberra, Australia

Beijing Normal University, China

\section{Laura Blythe Liu}

Indiana University-Purdue University, Columbus, USA

\section{Qiong Li*}

Beijing Normal University, China

\begin{abstract}
Teacher job satisfaction plays a key role in influencing a quality teaching workforce and student success. This article presented an analytical framework comprising teacher, classroom and school factors, and tested it by applying a three-level modeling technique with data drawn from 11 high-performing systems that participated in Teaching and Learning International Survey (TALIS) 2013. The quantitative results show that: (1) at the

* Corresponding author

Center for Teacher Education Research, Key Research Institute of Ministry of Education, Beijing Normal University, Beijing, China

Email: qiongli@bnu.edu.cn

Funding

Funding was supported by Key Research Institute of Humanities and Social Sciences in Universities, Ministry of Education, China (Grant Number: 19JJD880001). However, the findings and opinions expressed in the article do not necessarily reflect the positions of the funding agencies.
\end{abstract}


teacher level, higher self-efficacy is associated with higher job satisfaction; more effective professional development and collaboration are associated with higher job satisfaction; mid-career teachers tend to be the least satisfied group compared with young and old teachers. (2) at the classroom level, teaching larger classes is associated with lower satisfaction, while teaching classes with higher percentage of low achievers or low socioeconomic students is associated with lower satisfaction; (3) at the school level, student-teacher relationship is significantly positively associated with job satisfaction. The article concludes with implications for policy makers and educators across countries.

\section{Keywords}

Job satisfaction, self-efficacy, professional development, student-teacher relationship, principal leadership, high-performing systems

\section{Introduction}

For the last decade the Organisation for Economic Co-operation and Development's (OECD) Program for International Student Assessment (PISA) has been regarded as the world's 'premier yardstick of education quality', with quality interpreted in economic terms as a proxy for human-knowledge capital (Auld, Rappleye \& Morris 2018). More and more countries and education systems have looked beyond their own borders through the international rankings of student achievements of PISA for evidence of the most successful and efficient educational policies and practices (Pang \& Wang 2016; OECD 2011). Thus, much attention has been drawn to the success of education systems that consistently rank high with regard to quality and equality on the PISA, so-called high-performing education systems (e.g. Jensen Jensen, Sonnemann, Roberts-Hull, and Hunter 2016). A growing body of research suggests that high-performing education systems achieve a set of coherent principles for promoting and sustaining professional learning and development of teachers and school leaders. These cornerstones enable quality teaching and learning to take place (Barber \& Mourshed. 2007; Darling-Hammond, et al. 2017; Tucker 2011).

Teacher quality is undoubtedly of great importance to student success in these highperforming systems (e.g. Darling-Hammond et al. 2017; Tucker 2011). Teachers' job satisfaction, a sense of enjoyment and fulfillment derived from work activities (Locke 1969, Skaalvik \& Skaalvik 2010), plays a critical role in influencing the quality of the 
teaching workforce, and consequently impacting student academic achievement and a well-rounded education (Tang, He, Liu \& Li 2018). Low teacher job satisfaction is linked to an increased likelihood of low morale (Collie, Shapka \& Perry 2012), a low sense of wellbeing (Tang et al. 2018), and intent to leave the profession (Ingersoll and Strong 2001). Despite the emerging evidence of the relationship between teachers' job satisfaction and teacher self-efficacy, wellbeing and retention, as well as student learning in one context (Klassen and Chiu 2010; Collie, Shapka and Perry 2012), relatively little is known about teachers' job satisfaction from a cross-cultural perspective. While there are considerable discussions about international student assessment comparisons, there is limited understanding about what teachers in high-performing systems actually do, particularly what contributes to job satisfaction. Therefore, there is an imperative to develop enriched and contextualized understandings of teachers' job satisfaction from diversified perspectives. Data from the large-scale Teaching and Learning International Survey (TALIS) launched by OECD in 2013 have provided the potential to analyze teachers' job satisfaction across different education systems.

Moreover, quality teaching and learning do not happen in a vacuum, and academic success does not occur unless in contexts where policymakers, practitioners and researchers work together to uplift the profession and promote each student's well-rounded development. Thus, empirical analyses of teachers' job satisfaction in this study concur with the teaching and learning eco-systemic accounts (Elliott et al. 2018). The purpose is to examine teacher, classroom and school factors as a holistic system in education through multilevel analysis that might relate to teachers' job satisfaction in high-performing systems drawn upon data from TALIS 2013 (OECD 2014b).

The study seeks to make a contribution to the literature by developing an analytical framework about teacher job satisfaction and testing it with a three-level modeling technique. First, we pooled the data together from selected high performing systems to search for common factors that may influence teacher job satisfaction from a cross-national perspective. As revealed in the PISA 2012 report (OECD 2014a), high-performing education systems are those with mean performance or share of top performers above the OECD's average. Among 18 high performing systems, 11 participated in TALIS 2013. Most of the previous studies have examined teacher job satisfaction in samples drawn from individual countries, hindering research utilization by policy makers and educators in different contexts (Caprara et al. 2003; Klassen and Chiu 2010; Skaalvik and Skaalvik 2011). A few studies with international data are geographically limited to regions like Europe or Asia (Klassen, Usher and Bong 2010). This study intends to fill 
the gap by providing multilevel analyses of multiple factors in a global sense.

Second, we include key factors at the teacher, classroom, and school levels to develop a more comprehensive analytical framework about teacher job satisfaction than what has been used previously. As the TALIS 2013 report (OECD 2014) showed, several factors, ranging from teacher background to teacher experience, impact job satisfaction. However, most studies only focused on one or two core factors, such as self-efficacy, teacher-student relationship, or school climate (Caprara et al. 2003; Van Maele and Van Houtte 2012). Only a few studies combined multiple factors from teacher, classroom or school aspects, but they focused on one cultural context (Crossman and Harris 2006). Hence, it is a worthwhile endeavor to examine a broader range of factors that influence teacher job satisfaction across different education systems.

Third, we build a three-level explanatory model to explain the variance in teacher job satisfaction at the teacher, school, and country levels. Multilevel analysis is frequently used in dealing with international data, but relevant studies are mostly based on two-level modeling, with teachers nested in schools (Zhou 2014; Gumus and Bellibas 2016). In this study, we examine key factors shaping teacher job satisfaction in 11 high performing systems, including Australia, Estonia, Finland, Japan, Korea, Netherlands, New Zealand, Poland, Singapore, Canada, Shanghai-China (OECD 2014a). We have formed a dataset with TALIS 2013 data drawn from these high-performing systems. We aim to build on this work in future research by examining key factors and strategies to enhance teacher job satisfaction in some other countries that share educational challenges due to socioeconomic or other contributing factors.

The research questions addressed in this study include: (1) what teacher level variables are significant predictors of teacher satisfaction in high-performing systems? (2) What classroom level variables are significant predictors of teacher satisfaction in high-performing systems? (3) When combining both teacher and classroom level variables, what are significant predictors of teacher satisfaction in schools in high-performing systems?

\section{Literature review}

Teacher job satisfaction is defined as teachers' affective reactions to their work and teaching role (Skaalvik and Skaalvik 2010). There is a voluminous literature focusing on conceptualizing and measuring the concept. Concerning the measurement of job satisfaction, 
some single-dimension scales have been developed and validated (Caprara et al. 2003; Skaalvik and Skaalvik 2011). However, in PISA and TALIS, a composite scale with two dimensions (satisfaction with work environment and satisfaction with profession) was preferred (OECD 2012). Many researchers have investigated the varied factors influencing teacher job satisfaction, ranging from psychological, demographic, to environmental factors (Caprara et al. 2003; Klassen and Chiu 2010; Skaalvik and Skaalvik 2010). Recent years have witnessed a growing body of cross-national studies on the related topics (Klassen and Chiu 2010; Klassen, Usher, and Bong, 2010). However, most of these studies merely made comparisons between two or three countries, lacking a systematical analysis by applying multi-level techniques to model the pooled data.

Figure 1 presents an analytical framework of teacher job satisfaction in this study that comprises ten factors at three levels. Teacher level predictors include gender, work experience, self-efficacy, professional development, professional collaboration. Classroom level predictors comprise class size and class composition. School level predictors consist of teacher-student relations, principal leadership, student-teacher ratio. The followings sections review the relevant literature and explicate the individual, class and school factors in association with teacher job satisfaction.

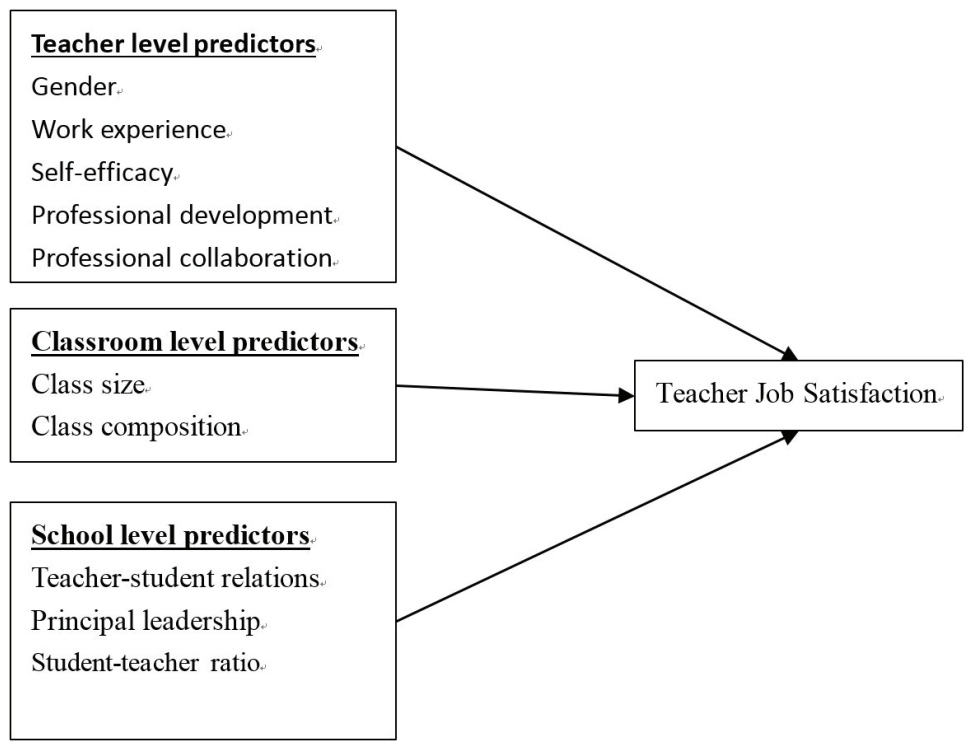

Figure 1. Analytical Framework of Teacher Job Satisfaction 


\section{Individual Factors and Job Satisfaction}

\section{Personal Characteristics}

Personal characteristics such as gender, age, degree, and work experience are the most common factors examined in previous studies, usually as control variables. Due to the high correlation between age and work experience, and given the fact that most teachers in our sample (90\%) achieved International Standard Classification of Education (ISCED) level 5A, we draw the attention mainly to gender and work experience in our study.

Previous studies on gender and job satisfaction revealed seemingly contradictory findings in different cultural contexts. An early study of United Kingdom high school teachers found that male teachers were slightly more satisfied than female teachers (Crossman and Harris 2006). However, in a sample of primary and secondary school teachers in Norway, Skaalvik and Skaalvik (2011) showed that female teachers had significantly higher job satisfaction than male teachers. More recently, a comparative analysis with data from the Trends in International Mathematics and Science Study (TIMSS) showed that female teachers were more satisfied than their male counterparts in both Japan and the United States (Reeves, Pun and Chung 2017).

Moreover, the association between job satisfaction and work experience has been tested in many studies, with some revealing significant results (Reeves, Pun and Chung 2017), and others showing insignificant association (Moe, Pazzaglia and Ronconi 2010). In fact, the results of an early study by Crossman and Harris (2006) showed that teachers with 11-20 years of teaching experience were the least satisfied group. This finding suggests a non-linear relationship, perhaps even an inverse relationship between work experience and job satisfaction. The finding may also reflect the lack of career growth opportunities that could enhance job satisfaction over time in the field of teaching. In either case, we may anticipate work experience to have a non-linear or inverse relationship with job satisfaction.

\section{Self-Efficacy}

Self-efficacy has the closest relationship with job satisfaction, and the variables are often studied together (Caprara et al. 2003; Moe, Pazzaglia and Ronconi 2010; Malinen and Savolainen 2016). In the TALIS 2013 report (OECD, 2014b), self-efficacy and job satisfaction were treated as two outcome variables. Most studies confirm that self-efficacy has a strong and positive association with job satisfaction. Caprara et al. (2003) conducted a comprehensive study on the underlying mechanism for this association, and 
found that self-efficacy has an indirect effect on job satisfaction via teachers' perceptions of principals, students, school staff and colleagues. In a later study, Klassen and Chiu (2010) used the short form of Teachers' Self-Efficacy Scale (TSES) developed by Tschannen-Moran and Woolfolk Hoy (2001). The findings showed that all three dimensions (classroom management, instructional strategies, and student engagement) were significantly and positively associated with job satisfaction in a sample of Canadian teachers.

International surveys like TALIS also included the adapted version of TSES in the teacher questionnaire. Some empirical studies utilised these data for cross-national analysis on self-efficacy (Fackler and Malmberg 2016), but only a few studies closely examined its link with job satisfaction. In a study using TALIS 2008 data to analyze self-efficacy in 23 countries, Vieluf, Kunter and De Vijver (2013) found a high correlation $(\mathrm{r}=0.4)$ between self-efficacy and job satisfaction across 23 countries including high performing countries like Korea and Norway. However, the researchers did not apply multi-level modeling techniques to provide further evidence on the correlation. Therefore, there is a need to further investigate this relationship in the current study.

\section{Professional Development and Collaboration}

Professional learning is a career-long need for teachers. Professional learning takes different forms, such as professional development activities, professional collaboration and peer support. Research has shown that participation in professional development activities can enhance teachers' belief in and commitment to teaching (Desimone 2009), and can thereby make them feel more fulfilled and satisfied with their jobs. According to the results from the TALIS 2013 (OECD 2014b), professional development activities like participating in an induction program or having a mentor were positively associated with job satisfaction in many educational systems.

Professional collaboration is also an important form of professional learning and can enhance communication and professional dialogue between teachers. In an early study with four case schools in Australia, Johnson (2003) found that most teachers held positive attitudes towards professional collaboration, because it provided teachers with opportunities to learn from each other. With longitudinal data from German teachers, Wolgast and Fischer (2017) showed that frequent cooperation in teaching reduced teacher stress in later years, and this relationship was mediated by enhanced colleague support. Using TIMSS data, Reeves, Pun and Chung (2017) examined the effect of different collaborative practices on job satisfaction and confirmed that frequently visiting another classroom was significantly associated with higher job satisfaction. 


\section{Classroom Factors and Job Satisfaction}

The classroom is the place where teaching and learning happen. Classroom characteristics are directly related to teachers' workload and work stress. For instance, a large class size will increase the time teachers spend on classroom management, thus reduce their efficacy and job satisfaction. However, empirical evidence on this aspect is not consistent. Using TALIS 2008 data, Reeves, Pun and Chung (2017) revealed that larger class size had a negative effect in Japan but a positive effect in the United States; both relationships lacked statistical significance. In the results of TALIS 2013, a significant association was found in one high performing country (Estonia) and other three countries (Latvia, Malaysia and England), and the association was negative in Estonia, Malaysia and England (OECD 2014b).

Class composition is also important to teachers' job satisfaction. Many studies have shown that, when teaching low-achieving students, teachers tend to feel more stressed and less satisfied (Major 2012). A consistent negative effect was documented in the TALIS 2013 report (OECD 2014b). Similarly, in classrooms with high percentages of students from families of low socioeconomic status (SES), teaching can become a more difficult job, due to academic and social challenges students may experience (Yeo et al. 2008). Additionally, in a large-scale study of job satisfaction and school context, Johnson et al. (2012) found that correlations between low satisfaction and low SES conditions were correlated with the unsupportive work environment that may be found in low SES schools. However, a positive work culture in which teachers felt supported by the principal, leadership team, and colleagues played a stronger role in teacher job satisfaction. These factors rose above student demographics and school conditions. The finding provides hope that enhancing school culture can ultimately attract high quality teachers and turn around struggling schools.

\section{School Factors and Job Satisfaction}

School characteristics and environment determine teacher's perception of teaching profession. Some research that has examined key factors impacting teacher job satisfaction concludes that school climate variables (e.g. student-teacher ratio, school size, public vs. private) are less significant in shaping job satisfaction than relational factors (e.g. teacher-student relationship, teacher-colleague relationships, school leadership) (Collie, Shapka and Perry 2012; Johnson et al. 2012; Skaalvik and Skaalvik 2011). Therefore, in the following sections, we mainly discuss the relational factors of job satisfaction. 


\section{Teacher-Student Relationship}

The relationship between teachers and students is the most important relationship among all stakeholders in a school. Good teacher-student relationships help to create better environments for teaching and learning, and therefore make both teachers and students better off. In a study on Canadian teachers, Collie, Shapka and Perry (2012) found teacher-student relationships were more strongly associated with teacher job satisfaction than school climate, which is also an important factor. This positive association was highlighted in the TALIS 2013 report (OECD 2014b) through country-specific multiple regressions, where significantly positive estimates were found in all country samples, with magnitudes ranging from 0.24 to 0.42 . Hence, it is reasonable to expect that, in our sample consisting of 11 high-performing systems, teacher-student relationships will also have a significantly positive association with job satisfaction.

\section{Principal Leadership}

While student-teacher relationships are consistently found to have the most significant impact on teacher job satisfaction, the role of school leadership and relationship between principals and teachers also are significant variables. In an early study with a large sample of K-12 teachers in the United States, Wahlstrom and Louis (2008) found that shared leadership increased effective teaching practices. This implies that teachers are more satisfied with shared leadership than with an authoritarian style, since more support can be found in a positive school culture created by shared leadership. This observation has been partly proven in a study conducted by Tickle, Chang and Kim (2011), who found that administrative support from principals was significantly and positively associated with teachers' job satisfaction in the United States. However, due to various definitions and measurements of leadership, its relationship to teachers' job satisfaction is rather complex. In TALIS 2013, leadership is measured by two separate variables: one is distributed leadership; the other is instructional leadership (OECD 2014b). The effect of instructional leadership was significantly positive in only three countries. In a similar vein, a relevant study by Fackler and Malmberg (2016) showed that, at the international level, distributed leadership had a significantly positive effect on self-efficacy, but instructional leadership did not. Therefore, we expect distributed leadership to be positively associated with job satisfaction, whereas instructional leadership may not. 


\section{Method}

\section{Sample}

This quantitative study is based on TALIS 2013 data (OECD 2014b), covering a total of 32 countries, of which 10 are non-OECD countries. TALIS is the first large-scale international survey with a focus on the teaching workforce, and it investigates varied aspects concerning teaching conditions and learning environments. Although participating countries must take part in the survey at the lower secondary level (ISCED 2), which is the target of the PISA test, participating countries are also encouraged to take part in surveys at the primary or higher secondary level (ISCED 1 or 3) on a voluntary basis. For the 2013 survey, to ensure representative samples for each participating country, two-stage random sampling was applied, with the first stage sampled at the school level (normally 200 schools) and the second stage sampled at the teacher level (normally 20 teachers in each school). Questionnaires were administered to the participating schools. Principals were asked to complete the school questionnaire covering conditions, leadership, and climate, and teachers were asked to complete the teacher questionnaire covering background information, professional development, job satisfaction, and teacher student relations (OECD 2014c).

In this study, we selected data from the lower secondary schools (ISCED 2) in 11 high-performing systems and merged the school data (from the principal questionnaire) with the teacher data (from the teacher questionnaire) for all countries to generate a full dataset containing variables at all three levels of analysis (teacher, classroom, and school).

Handling missing values is a difficult task when conducting research with large-scale international data. The percentages of missing value on most variables were below $5 \%$, except $14.3 \%$ (class size) and professional development (13.1\%). Rather than list-wise deletion, we followed the research practices of Chiu and colleagues (Chiu et al. 2016; Chiu, Chow and Joh 2017) to apply Monto Carlo Markov Chain (MCMC) methods to impute the missing values. The final data for quantitative analysis had a sample size of 31067 teachers from 1860 schools in 11 educational systems. In the full sample, $65.57 \%$ of teachers are female, and the average work experience as a teacher is 16 years. Furthermore, $96.51 \%$ of teachers have a bachelor's degree or above (ISCED $5 \mathrm{~A}+$ ), demonstrating the high qualification of the teaching workforce in high-performing systems. Hence, there is no need to include a variable of educational level in the current study 


\section{Variables}

As shown in Table 1, our analytical framework includes four kinds of variables in the quantitative analysis. (1) Outcome variable: teacher job satisfaction; (2) Explanatory variables at the teacher level: gender, work experience, self-efficacy, professional development and professional collaboration. (3) Explanatory variables at the classroom level: class size, $\%$ of low achiever, \% of low SES students. (4) Explanatory variables at the school level: teacher-student relations, distributed leadership, public school, and student-teacher ratio.

Table 1. Variables and Their Descriptive Statistics

\begin{tabular}{|l|c|c|c|c|c|}
\hline \multicolumn{1}{|c|}{ Variable } & Mean & SD & Min & Max & Cronbach's $\alpha^{1}$ \\
\hline job satisfaction & 11.611 & 1.86 & 4.25 & 15.1 & $0.75 \sim 0.84$ \\
\hline gender & 0.6557 & 0.48 & 0 & 1 & NA \\
\hline work experience & 16.002 & 10.5 & 0 & 57 & NA \\
\hline self-efficacy & 11.748 & 2.08 & 3.74 & 16.1 & $0.82 \sim 0.94$ \\
\hline professional development & 8.9771 & 1.97 & 0.82 & 16.5 & $0.59 \sim 0.78$ \\
\hline professional collaboration & 8.9941 & 1.98 & 3.27 & 15.5 & $0.45 \sim 0.70$ \\
\hline class size & 26.965 & 11 & 1 & 95 & NA \\
\hline$\%$ low achievers & 2.6987 & 0.96 & 1 & 5 & NA \\
\hline$\%$ low SES students & 2.3124 & 0.94 & 1 & 5 & NA \\
\hline Teacher student relations & 13.17 & 0.28 & 12.42 & 14.66 & $0.71 \sim 0.86$ \\
\hline distributed leadership & 12.201 & 2.09 & 3.67 & 20.1 & $0.50 \sim 0.81$ \\
\hline public school & 0.8404 & 0.37 & 0 & 1 & NA \\
\hline Student teacher ratio & 14.037 & 22.1 & 0.09 & 558 & NA \\
\hline
\end{tabular}

Notes: The range of Cronbach's $\alpha$ for the sampled 11 countries.

\section{Teacher Job Satisfaction}

In TALIS 2013, a four-point scale $(1=$ strongly disagree, $2=$ disagree, $3=$ agree, $4=$ strongly agree) with 8 items was used to measure teacher job satisfaction. The scale consists of two equal subscales - Satisfaction with Work Environment (e.g., I enjoy working at this school) and Satisfaction with Profession (e.g., The advantages of being a teacher clearly outweigh the disadvantages). The Cronbach' alpha of the teacher job satisfaction scale ranges from 0.75 to 0.84 among the 11 countries, demonstrating a high reliability of the measurement. A derived variable of JS scale was provided in 
TALIS 2013 dataset (OECD 2014b). It was created by first computing the factor scores of CFA results of each subscale for each country, then rescaling them to a convenience metric, and finally taking average of the rescaled factor scores of all subscales. Detailed process for all the derived variables can be found in TALIS 2013 Technical Report (OECD 2014c).

\section{Teacher-Level Variables}

TALIS provides rich data at the teacher level, and two groups of variables are included in our analysis. One group of variables represents personal characteristics such as gender and work experience. Gender is coded as a binary variable $(0=$ male, $1=$ female $)$. Work experience is determined by asking how many years the participants have been working as a teacher.

The second group of variables consists of three derived variables from the TALIS 2013 teacher questionnaire: self-efficacy, professional development, and professional collaboration. Self-efficacy is an important domain and consists of three components, namely efficacy in classroom management, efficacy in instruction, and efficacy in student engagement. Teachers rated a total of 12 items on a four-point scale $(1=$ not at all; $2=$ to some extent; $3=$ quite a bit; $4=\mathrm{a}$ lot) to indicate the extent to which they do things in classroom management (e.g., control disruptive behavior in the classroom), in instruction (e.g., craft good questions for my students), and in student engagement (e.g., get students to believe they can do well at school work).

Effective professional development was measured by asking teachers to rate their professional development activities during the last 12 months. The measure included four items (e.g., opportunities for active learning methods [not only listening to a lecturer]) on a four-point scale $(1=$ not in any activities; $2=$ yes, in some activities; $3=$ yes, in most activities; 4 = yes, in all activities).

Professional collaboration is measured by asking teachers to report the frequencies with which they engage in certain collaborative activities (e.g., teach jointly as a team in the same class). The scale consists of four items, each on a six-point scale $(1=$ never; $2=$ once a year or less; $3=2-4$ times a year; $4=5-10$ times a year; $5=1-3$ times a month; 6 = once a week or more). A derived variable of self-efficacy, professional development, professional collaboration was provided in TALIS 2013 dataset. 


\section{Classroom-Level Variables}

TALIS 2013 also collected data on characteristics of the class that each teacher taught. Three variables are included in our analysis: class size, percentage of low achievers, and percentage of low SES students. Class size is the number of students in the target classroom reported by teachers. Percentages of low achievers and low SES students were measured by teachers' reports on a five-point scale $(1=$ none; $2=1 \%$ to $10 \% ; 3=11 \%$ to $30 \% ; 4=31 \%$ to $60 \% ; 5=$ more than $60 \%$ ).

\section{School-Level Variables}

School-level variables include three from the principal questionnaire (school type, teacher-student ratio, distributed leadership), and one from teacher questionnaire (teacher-student relationship). School type is a binary variable $(1=$ public, $0=$ private). The index of student-teacher ratio was calculated by dividing the number of students by the number of teachers. Distributed leadership was measured using three items (e.g., This school provides staff with opportunities to actively participate in school decisions) scored on a four-point scale $(1=$ strongly disagree; $2=$ disagree; $3=$ agree; $4=$ strongly agree). Data on teacher-student relationships was collected on the teacher questionnaire using a four-point scale $(1=$ strongly disagree; $2=$ disagree; $3=$ agree; $4=$ strongly agree); there were four items (e.g., In this school, teachers and students usually get on well with each other). A derived variable of teacher-student relationships at teacher level is provided in the TALIS 2013 dataset. We aggregated this variable at the school level and then used it as a school level variable to measure teacher-student relationships.

\section{Explanatory Models}

The aim of the study is to explore factors at the teacher, classroom and school levels that are associated with teacher job satisfaction in high-performing systems. To address our research questions, we prepared and analysed the data for three-level modeling, with teachers nested in schools that were nested in countries.

To answer our first research question on factors at the teacher level, we built the three-level model specified as equation (1). 


$$
\begin{gathered}
J S_{j i k}=b_{0}+b_{1} \text { gender }_{i j k}+b_{2} \text { work_experience }_{i j k}+b_{3} \text { self_efficacy }_{i j k} \\
+b_{4} \text { professional development }_{i j k}+b_{5} \text { professional collaboration }_{i j k} \\
+u_{i j k}+v_{i j}+e_{k}
\end{gathered}
$$

where $J S_{j i k}$ denotes the job satisfaction of teacher $i$ in school $j$ in country $k, b_{0}$ denotes the intercept (or constant), $b_{i}(i \neq 0)$ denotes the estimated coefficient of the variable, and $u_{i j k}, v_{i j}, e_{k}$ denote residuals at the teacher, school, and country levels, respectively.

To answer our second research question on what classroom factors are associated with teacher job satisfaction, we modified equation (1) by introducing class-level variables, building the three-level model as equation (2):

$$
\begin{aligned}
J S_{j i k}= & b_{0}+b_{1} \text { gender }_{i j k}+b_{2} \text { work_experience }_{i j k}+b_{3} \text { self_efficacy }_{i j k} \\
& +b_{4} \text { professional_development }_{i j k}+b_{5} \text { professional_collaboration }_{i j k} \\
& +b_{6} \text { class_size }_{i j k}+b_{7} \% \text { low_achiever }_{i j k}+b_{8} \% \text { lowe_ses }_{i j k} \\
& +u_{i j k}+v_{i j}+e_{k}
\end{aligned}
$$

Finally, to answer our last research question on school-level factors, school-level variables were introduced to the equation to make the final equation (3):

$$
\begin{aligned}
& J S_{j i k}=b_{0}+b_{1} \text { gender }_{i j k}+b_{2} \text { work_experience }_{i j k}+b_{3} \text { self_efficacy }_{i j k} \\
& +b_{4} \text { professional_development }_{i j k}+b_{5} \text { professional_collaboration }_{i j k}+b_{6} \text { class_size }_{i j k} \\
& +b_{7} \% \text { low_achiever }_{i j k}+b_{8} \% \text { lowe_ses }_{i j k} \\
& +b_{9} \text { teacher_student_relations } j_{j k}+b_{10} \text { distributed_leadership }_{j k} \\
& +b_{11} \text { public }_{j k}+b_{12} \text { studuent_teacher_ratio }_{j k} \\
& +u_{i j k}+v_{i j}+e_{k}
\end{aligned}
$$

\section{Results}

\section{Results of Correlation Analysis of Variables}

Table 2 presents the descriptive statistics for each variable and the correlations between variables. Considering the extraordinarily large sample size, we marked only those of 
significance level $p<0.01$ with *. As the first column shows, job satisfaction is significantly correlated with all predictors except gender, work experience, and studentteacher ratio.

Table 2. Correlations Between Variables

\begin{tabular}{|c|c|c|c|c|c|c|c|c|c|c|c|c|c|}
\hline & 1 & 2 & 3 & 4 & 5 & 6 & 7 & 8 & 9 & 10 & 11 & 12 & 13 \\
\hline 1 & 1 & & & & & & & & & & & & \\
\hline 2 & 0.01 & 1 & & & & & & & & & & & \\
\hline 3 & -0.01 & $-0.02 *$ & 1 & & & & & & & & & & \\
\hline 4 & $0.25^{*}$ & $0.09 *$ & $0.05 *$ & 1 & & & & & & & & & \\
\hline 5 & $0.12 *$ & $0.05^{*}$ & $-0.04 *$ & $0.24 *$ & 1 & & & & & & & & \\
\hline 6 & $0.14 *$ & 0.01 & $-0.05 *$ & $0.20^{*}$ & $0.32 *$ & 1 & & & & & & & \\
\hline 7 & $-0.13 *$ & $-0.07 *$ & $-0.10 *$ & $-0.05 *$ & $0.07 *$ & $0.12 *$ & 1 & & & & & & \\
\hline 8 & $-0.07 *$ & $-0.02 *$ & $-0.09 *$ & $0.02 *$ & -0.00 & $0.05^{*}$ & $0.03 *$ & 1 & & & & & \\
\hline 9 & $-0.07 *$ & $-0.03 *$ & $-0.05 *$ & $0.08^{*}$ & $0.03 *$ & $0.07 *$ & 0.01 & $0.49 *$ & 1 & & & & \\
\hline 10 & $0.41 *$ & $0.02 *$ & -0.01 & $0.26^{*}$ & $0.17^{*}$ & $0.17^{*}$ & $-0.04 *$ & $-0.06^{*}$ & $-0.07 *$ & 1 & & & \\
\hline 11 & $-0.05^{*}$ & $0.12 *$ & 0.01 & $0.18^{*}$ & $0.11^{*}$ & 0.01 & -0.01 & $-0.02 *$ & $0.07 *$ & -0.00 & 1 & & \\
\hline 12 & $-0.07 *$ & $0.07 *$ & 0.01 & $-0.05^{*}$ & -0.00 & $0.04 *$ & $-0.02 *$ & $0.10^{*}$ & $0.17 *$ & $-0.07 *$ & $0.06^{*}$ & 1 & \\
\hline 13 & -0.01 & $-0.04 *$ & -0.00 & $-0.10^{*}$ & $-0.04 *$ & $0.02 *$ & $0.106 *$ & -0.00 & $-0.00 *$ & 0.01 & $-0.11 *$ & $0.02 *$ & 1 \\
\hline
\end{tabular}

Notes: $1=$ job satisfaction (JS), $2=$ gender, $3=$ work experience, $4=$ self-efficacy, $5=$ professional development, $6=$ professional collaboration, $7=$ class size, $8=\%$ low achievers, $9=\%$ low SES students, $10=$ teacher-student relations, $11=$ distributed leadership, $12=$ public, $13=$ student-teacher ratio. ${ }^{*}=p<0.01$.

Among the five variables at the teacher level, self-efficacy, professional development, and professional collaboration have significantly positive correlations with job satisfaction. The largest correlation can be found in self-efficacy $(\mathrm{r}=0.25)$, demonstrating its strong relationship with job satisfaction. Three classroom variables have significantly negative correlations with job satisfaction. Among the five variables at the school level, teacherstudent relationship has the strongest and most positive correlation with job satisfaction. However, quite surprisingly, distributed leadership has small but significantly negative correlations with job satisfaction, which seems to contradict the existing literature. Some further calculations of the correlations between distributed leadership and job satisfaction in system-specific samples showed that the negative correlation was only found in Australia and New Zealand. Similar results were documented in the TALIS 2013 report (OECD 2014b), hence, it is worth examining in multi-level modeling. 


\section{Results of Three-Level Modeling}

A conventional first step in multi-level modeling is to run the baseline model with no explanatory variables (also known as the null model) to check applicability. The result of this model is summarized as Model 0 in Table 3. The variance of residuals at each level is statistically significant, demonstrating substantial variance between schools and systems. The total variance is 3.486 , with a large proportion at teacher level $(83.30 \%)$, and a proportion at school $(5.90 \%)$ and country level (10.90\%) respectively, which confirms the appropriateness of using three-level modeling for further analysis.

Table 3. Results of Three-Level Linear Regressions

\begin{tabular}{|c|c|c|c|c|}
\hline & Model 0 & $\begin{array}{l}\text { Model 1: } \\
\text { +teacher }\end{array}$ & $\begin{array}{c}\text { Model 2: } \\
\text { +classroom }\end{array}$ & $\begin{array}{c}\text { Model } \\
3:+ \text { school }\end{array}$ \\
\hline $\begin{array}{l}\text { Fixed part } \\
\text { Intercept }\end{array}$ & $\begin{array}{l}11.728^{*} \\
(0.195)\end{array}$ & $\begin{array}{l}7.973^{*} \\
(0.117)\end{array}$ & $\begin{array}{l}8.833^{*} \\
(0.122)\end{array}$ & $\begin{array}{c}4.103^{* * *} \\
(0.492)\end{array}$ \\
\hline Gender & & $\begin{array}{c}0.044 \\
(0.042)\end{array}$ & $\begin{array}{c}0.027 \\
(0.043)\end{array}$ & $\begin{array}{c}0.030 \\
(0.043)\end{array}$ \\
\hline Work experience & & $\begin{array}{l}-0.060^{*} \\
(0.008)\end{array}$ & $\begin{array}{l}-0.061^{*} \\
(0.007)\end{array}$ & $\begin{array}{l}-0.060^{*} \\
(0.007)\end{array}$ \\
\hline Work experience ${ }^{2}$ & & $\begin{array}{l}0.152 * \\
(0.019)\end{array}$ & $\begin{array}{l}0.152 * \\
(0.017)\end{array}$ & $\begin{array}{l}0.151^{*} \\
(0.018)\end{array}$ \\
\hline Self-efficacy & & $\begin{array}{l}0.196^{*} \\
(0.017)\end{array}$ & $\begin{array}{l}0.195^{*} \\
(0.018)\end{array}$ & $\begin{array}{l}0.194 * \\
(0.018)\end{array}$ \\
\hline Professional development & & $\begin{array}{l}0.084 * \\
(0.007)\end{array}$ & $\begin{array}{l}0.082 * \\
(0.007)\end{array}$ & $\begin{array}{l}0.082^{*} \\
(0.007)\end{array}$ \\
\hline Professional collaboration & & $\begin{array}{l}0.119^{*} \\
(0.009)\end{array}$ & $\begin{array}{l}0.126^{*} \\
(0.009)\end{array}$ & $\begin{array}{l}0.125^{*} \\
(0.009)\end{array}$ \\
\hline Class size & & & $\begin{array}{l}-0.008^{*} \\
(0.001)\end{array}$ & $\begin{array}{l}-0.007 * \\
(0.001)\end{array}$ \\
\hline$\%$ Low achiever & & & $\begin{array}{l}-0.155^{*} \\
(0.025)\end{array}$ & $\begin{array}{l}-0.153^{*} \\
(0.025)\end{array}$ \\
\hline$\%$ Low SES students & & & $\begin{array}{l}-0.111^{*} \\
(0.016)\end{array}$ & $\begin{array}{l}-0.104^{*} \\
(0.019)\end{array}$ \\
\hline Teacher-student relations & & & & $\begin{array}{l}0.354^{*} \\
(0.033)\end{array}$ \\
\hline
\end{tabular}




\begin{tabular}{|l|c|c|c|c|}
\hline Distributed leadership & & & & 0.011 \\
& & & & $0.009)$ \\
\hline Public & & & & -0.115 \\
& & & & $0.086)$ \\
\hline Student-teacher ratio & & & & 0.000 \\
& & & & $(0.000)$ \\
\hline Random part & & & & \\
Country & 0.380 & 0.371 & 0.361 & 0.353 \\
& $(0.081)$ & $(0.141)$ & $(0.133)$ & $(0.136)$ \\
\hline School & 0.204 & 0.178 & 0.153 & 0.141 \\
& $(0.026)$ & $(0.017)$ & $(0.016)$ & $(0.015)$ \\
\hline Teacher & 2.902 & 2.634 & 2.601 & 2.601 \\
& $(0.114)$ & $(0.102)$ & $(0.106)$ & $(0.106)$ \\
\hline$-2 * \log$ pseudolikelihood & 122730 & 119681 & 119168 & 119097 \\
\hline$\Delta-2 * \log$ pseudolikelihood & & 3048 & 513 & 71 \\
\hline$\%$ Variance & Variance & Explained & Explained & Explained \\
\hline Country & proportions & Variance & Variance & Variance \\
\hline School & $10.9 \%$ & $2.2 \%$ & $2.7 \%$ & $2.22 \%$ \\
\hline Teacher & $5.9 \%$ & $13.0 \%$ & $13.7 \%$ & $7.84 \%$ \\
\hline
\end{tabular}

Notes: 1. Robust errors in parentheses. 2. ${ }^{*} \mathrm{p}<0.01$.

As specified by our explanatory models, we added teacher, classroom, and school variables into the baseline model step by step. The results in Models 1-3 are presented in Table 3. For the first step, five variables at teacher level are added. The model fit is much improved $(\Delta-2 \mathrm{LL}=3048$, and the total variance explained by these newly added variables is $2.20 \%, 13.00 \%, 9.20 \%$, respectively at the teacher, school, and country levels. Gender has a positive but insignificant association with job satisfaction, demonstrating that female teachers tend to be equally satisfied as their male colleagues statistically.

Work experience has a nonlinear association with job satisfaction, where the linear part is negative $(b=-0.60, p<0.01)$ and the quadric part is positive $(b=0.152, p<0.01)$. This reveals that teachers' satisfaction with their jobs first drops till the midcareer, and then rises steadily. All three variables measuring teachers' attitude and practices have significantly positive associations with job satisfaction, with self-efficacy being the strongest predictor ( $b=0.196, p<0.01)$, followed by professional collaboration $(b=0.119, p<0.01)$ and professional development $(b=0.084, p<0.01)$. 
For the next step, modifying Model 1 with three classroom variables yields Model 2. The model fit is improved $(\Delta-2 \mathrm{LL}=513)$, and the total variance explained by the classroom variables is $2.7 \%, 13.7 \%$ and $1.2 \%$ respectively at the teacher, school, and system levels. Class size has a significantly negative association with job satisfaction ( $b=-0.008, p<0.01$ ), demonstrating that teachers with a larger number of students tend to feel less satisfied. Both the percentage of low achievers and the percentage of low SES students have significantly negative associations with job satisfaction, with the former ( $b=-0.155, p<0.01)$ being moderately stronger than the latter $(b=-0.111, p<0.01)$. Most previously added variables at the teacher level remain unchanged in terms of sign and magnitude, except the obvious shrink of gender coefficient.

For the final step, modifying Model 2 with five school variables yields Model 3. The model fit is slightly improved $(\Delta-2 \mathrm{LL}=71)$, which is partly caused by the unchanged variance at the teacher level $(0 \%)$. Total variance explained by the classroom variables is $2.22 \%$ and $7.84 \%$ respectively at the school and system levels. Teacher-student relationship has the most significantly positive association with job satisfaction $(b=0.354, p<0.01)$, demonstrating that teachers tend to feel more satisfied if they get on well with students. Distributed leadership has a positive association with job satisfaction $(b=0.011)$, which contrasts with the correlation results (Table 2), but lacks statistical significance. Similarly, the last two variables, school type and student-teacher ratio, were not significantly associated with job satisfaction. Additionally, the signs of all variables at the teacher and classroom levels remain unchanged, suggesting robustness of the final explanatory model.

\section{Discussion}

The present study utilised the TALIS 2013 data to explore teachers' job satisfaction in high-performing education systems. The results of three-level modeling revealed several variables that significantly predict teachers' job satisfaction, including self-efficacy and professional development at the teacher level, class size and composition at the classroom level, and student-teacher relationship at the school level.

\section{Self-Efficacy and Professional Development at the Teacher Level}

At the teacher level, self-efficacy and professional development reflect the motivation of staying in the teaching profession. The findings showed a strong connection between 
self-efficacy with job satisfaction in our cross-national data, hence, expanding the existing evidence from the studies with national samples (Vieluf et al. 2013). The importance of self-efficacy in the teaching profession has been emphasised in numerous studies (e.g. Caprara et al. 2003; Klassen and Chiu 2010), and its multidimensionality has been reflected in the TALIS 2013 framework as efficacy in classroom management, instruction and student engagement. The study suggests the possible ways for teachers to build their self-efficacy, which could, in turn, increase their job satisfaction.

Professional development is an important theme in teacher education, but few studies have examined its connection with teachers' job satisfaction (Wolgast and Fischer 2017; Reeves, Pun and Chung 2017). The present study confirmed the connection with a strong positive result. It suggests that participation in effective professional development activities, such as induction, mentoring, classroom observation visits, and workshops, is associated with high job satisfaction across the high-performing systems. Desimone (2009) summarized five core features of effective professional development: content focus, active learning, coherence, duration, and collective participation. This framework has been used as an important foundation for the design of professional development programs (Kennedy 2016; Zeggelaar, Vermeulen and Jochems 2017).

In particular, collective participation has gained increasing attention in recent years, accompanying the rise of professional learning communities (PLCs) in many high-performing systems, especially Mainland China, Hong Kong, Taiwan, Singapore and Korea in the Asia-Pacific region (Pang \& Wang 2016). For instance, in Mainland China, almost every school has a teaching group called a jiaoyanzu (Teaching research group), which usually gathers all teachers in the same subject or in the same grade together, to prepare lessons and discuss teaching-related issues (Sargent and Hannum 2009). Moreover, schools with structured, school-based, and research-oriented professional learning have been proven to be more effective (Wang 2015). Similar PLC practices exist in Japan, Korea, and Singapore, making such communities a feature of East Asian school systems (Darling-Hammond et al. 2017). Recent studies on school culture highlighted that collective teacher culture played an important role on influencing teacher satisfaction in some western countries like the US. (Stearns et al. 2015).

\section{Class Size and Composition at the Classroom Level}

The findings show that better work conditions for teachers in high-performing systems include smaller class size and lower percentages of low-achieving and low-SES students. 
Interestingly, class size was found to have a negative relationship with teachers' job satisfaction in Japan but not in the United States (Reeves, Pun and Chung 2017). This suggests that in high-performing systems, smaller class size could make teachers feel less stressful and more satisfied. This observation aligns with our findings.

Most high-performing systems have prescribed standards and regulations on the maximum number of students in the class. Educators understand that teachers can hardly handle a large number of students. The more students in one class, the less likely they achieve. Smaller class size helps reduce teachers' total workload, because there are fewer students to attend to, fewer problem behaviors in the classroom, and more time to engage students and solve their problems. This will reduce teachers' burnout and increasing their job satisfaction.

As for the class composition, it is unethical to exclude low-achieving or low-SES students in order to improve teacher job satisfaction. Nor would this guarantee an increase in job satisfaction. Rather, it is essential to understand why teachers feel unsatisfied and how to help them to manage students with diverse abilities or from diverse backgrounds. For instance, researchers have noted both pros and cons in grouping students by ability (Chiu, Chow and Joh 2017). Research evidence shows with professional development and support to differentiate instruction effectively, teachers are capable of handling diverse student needs in one classroom (Prast et al. 2018). In this case, ability grouping has its limitations and professional support would enhance job satisfaction.

\section{Student-Teacher Relations and Distributed Leadership at the School Level}

Interpersonal relation is essential to teachers' job satisfaction, and student-teacher relationship is undoubtedly the most important one among all the relationships. Many researchers confirm that teachers' relationships with students are not only the major source of their work stress, but also the major cause of their happiness (Spilt, Koomen and Thijs 2011). Positive relationships with students could satisfy teachers' emotional needs and make teaching feel more fulfilling and meaningful. Moreover, as Grayson and Alvarez (2008) pointed out, student-teacher relationships are the primary determinants of school climate, which influences teachers' job satisfaction. Consistent evidence from PISA studies reveals that high-performing systems usually have positive school climates featuring close relationships and strong bonds between students and teachers (OECD 2014a). This observation has been made across national contexts (e.g., China, Germany, Finland). While in some education systems, school violence against teachers is much 
more prevalent, which brings damage to the trust relation between teachers and students, or even forces teachers to quit their jobs (Espelage et al. 2013). Therefore, intervention policies should be considered in protecting teachers and help build teacher-student trust.

School leadership has been increasingly emphasised in today's educational context, since effective leadership leads to successful schools and higher teacher job satisfaction. In this study, distributed leadership was a positive predictor of job satisfaction as we expected, although the association was not statistically significant. There are two possible explanations. First, the perception of distributed leadership is quite sensitive to context and culture, and a one-size-fit-all measure of distributed leadership for all education systems was deemed to be imprecise and flawed (OECD 2014c). Second, data for distributed leadership in the TALIS 2013 surveys was collected from the principals participants while job satisfaction data from teachers. Hence, the psychological distance also made it hard to be statistically significant. Existing literature has repeatedly supported the importance of distributed leadership. As school administration becomes more complex, teachers tend to have a limited influence on what happens in schools (Tickle, Chang and Kim 2011; OECD 2014b). More authoritarian leadership means more supervision and less autonomy, which reduces teacher job satisfaction. This is consistent with our results, showing that distributed leadership tends to have a positive association with teachers' job satisfaction in high performing systems, although it is not statistically significant. To some extent, distributed leadership means more power given to individual teachers and more teacher participation in school administration. This empowerment gives teachers greater freedom to be innovative in classroom teaching and makes them feel heard and respected (Wahlstrom and Louis 2008). Moreover, research has shown that trust between teachers and principals is easier to build with distributed leadership, and the resulting trust throughout the school climate will make teachers more satisfied (Van Maele and Van Houtte 2012).

\section{Conclusion}

Based on TALIS 2013 data, the present study examined teachers' job satisfaction in 11 high-performing systems with teacher-level, classroom-level, and school-level variables using a three-level modeling approach. Despite differences in historical, educational, social, cultural contexts, the results reveal some commonalties in factors influencing teachers' job satisfaction. The primary findings are noteworthy. First, teachers with higher self-efficacy are more likely to report higher job satisfaction, and so do those teachers with more 
participation in effective professional development. Increasing teachers' job satisfaction is not just about making them happy and feel good about their teaching. It is important to enhance teachers' quality, retention and commitment to schools, thus ensuring student success. Policy makers and school leaders need to provide opportunities for teachers to grow, particularly encourage collaboration among teachers either through professional learning and shared classroom practice embedded in their daily work. Strategies such as observing classes and providing feedback, team teaching among colleagues could increase teachers' self-efficacy in classroom management, their quality of instruction and student engagement.

Second, challenging classroom circumstances have a significant impact on teachers' job satisfaction. Teachers having smaller class size are more likely to report higher job satisfaction, as well as those teachers teaching a class with a lower percentage of low academic and SES students. It is significant to build teacher capacity to effectively deal with challenging classes and students. Third, it is critical to support the development of trusting interpersonal relationships within the school environment. The findings demonstrate that positive teacher-student relationship and collegial relationship have a strong link with teachers' job satisfaction. School leaders should provide strong support for building an open and collaborative culture so that teachers are willing to engage with their colleagues and students. These key findings are informative for education administrators and policy-makers in both high performing and challenging education systems.

Nevertheless, the present study has limitations. First, the findings may pertain specifically to high-performing systems, as we did not include samples from other systems. In an increasingly interconnected world in the $21^{\text {st }}$ century, it is vital to address the uniqueness, diversity and dynamics of different nations in the international education research. Further research could be conducted to explore contributing factors to teacher job satisfactions across various educational systems.

Second, we utilised the MCMC imputation method to process the missing values. As for some variables with a high percentage of missing values (e.g., class size and professional development), the results should be interpreted with caution. With the progress in large-scale international surveys like TALIS, more high-quality data will become available in the future. Hence, further robust empirical evidence on teacher job satisfaction will be available.

Third, it should be noted that factors shaping teaching and learning are complex. In order to obtain reliable and valid explanations for teacher job satisfaction, various contextual factors should be further examined in our analytical model. Meanwhile, 
in-depth interviews and observations in schools, as well as document analysis could supplement the quantitative data analysis used in this study. Furthermore, research collaborations with researchers from other nations would provide an important international line of inquiry. Further studies could provide valuable insights for policy makers and educators about increasing teachers' quality and job satisfaction across different countries.

\section{References}

Auld, E., J. Rappleye, and P. Morris. 2018. "PISA for Development: how the OECD and World Bank shaped education governance post-2015." Comparative Education, 4: 1-23.

Barber, M., and M. Mourshed. 2007. "How the World's Best-Performing School Systems Come Out on Top." McKinsey \& Co., London.

Caprara, G. V., C. Barbaranelli, L. Borgogni, and P. Steca. 2003. "Efficacy beliefs as determinants of teachers' job satisfaction.” Journal of Educational Psychology 95(4): 821-832.

Chiu, M. M., B.W. Chow, C. Mcbride, and S. T. Mol. 2016. "Students' Sense of Belonging at School in 41 Countries Cross-Cultural Variability." Journal of Cross-Cultural Psychology 47(2): 175-196.

Chiu, M. M., W.Y. Chow, and S. W. Joh. 2017. "Streaming, tracking and reading achievement: A multilevel analysis of students in 40 countries." Journal of Educational Psychology 109(7): 915-934.

Collie, R. J., J. D. Shapka, and N. E. Perry. 2012. "School climate and social-emotional learning: Predicting teacher stress, job satisfaction, and teaching efficacy." Journal of Educational Psychology 104(4): 1189-1204.

Crossman, A., \& Harris, P. (2006). Job satisfaction of secondary school teachers. Educational Management Administration \& Leadership 34(1): 29-46.

Darling-Hammond, L., D. Burns, C. Campbell, A.L. Goodwin, K. Hammerness, et al. 2017. Empowered educators: How high-performing systems shape teaching quality around the world. San Francisco: Jossey-Bass.

Desimone, L. M. 2009. "Improving impact studies of teachers' professional development: Toward better conceptualizations and measures." Educational Researcher 38(3): 181-199.

Elliott, J., L. Stankov, J. Lee, and J. F. Beckmann. 2018. What did PISA and TIMSS ever do for us? : The potential of large scale datasets for understanding and improving educational practice. Comparative Education, 1-23. doi:10.1080/03050068.2018.15 
45386

Espelage, D. L., E. M. Anderman, V.E. Brown, A. Jones, K. L. Lane, et al. 2013. "Understanding and preventing violence directed against teachers: Recommendations for a national research, practice, and policy agenda." American Psychologist 68(2): 75-87.

Fackler, S., and L. Malmberg. 2016. “Teachers' self-efficacy in 14 OECD countries: Teacher, student group, school and leadership effects." Teaching and Teacher Education 56:185-195.

Grayson, J. L., and H.K. Alvarez. 2008. "School climate factors relating to teacher burnout: a mediator model." Teaching and Teacher Education 24:1349-1363.

Gumus, E., and M. S. Bellibas. 2016. "The effects of professional development activities on principals' perceived instructional leadership practices: multi-country data analysis using TALIS 2013.” Educational Studies 42(3): 287-301.

Ingersoll, R. M. \& Strong, M. (2011). The impact of induction and mentoring for beginning teachers; A critical review of the research. Review of Educational Research, 81(2): 201-233.

Jensen, B., J. Sonnemann, K. Roberts-Hull, and A. Hunter. 2016. Beyond PD: Teacher professional learning in high-performing systems. Washington, DC: National Center on Education and the Economy.

Johnson, B. 2003. "Teacher collaboration: Good for some, not so good for others." Educational Studies, 29:337-350

Johnson, S.M., M. A. Kraft, and J.P. Papay. 2012. "How context matters in high-need schools: The effects of teachers' working conditions on their professional satisfaction and their students' achievement." Teachers College Record 114(10): 1-39.

Kennedy, M. M. 2016. "How Does Professional Development Improve Teaching." Review of Educational Research 86(4): 945-980.

Klassen, R. M., and M. M. Chiu. 2010. "Effects on teachers' self-efficacy and job satisfaction: Teacher gender, years of experience, and job stress." Journal of Educational Psychology 102(3): 741-756.

Klassen, R.M., E. L. Usher, and M. Bong. 2010. "Teachers' collective efficacy, job satisfaction, and job stress in cross-cultural context." Journal of Experimental Education 78: 464-486.

Locke, E. A. 1969. "What is job satisfaction? Organizational Behavior and Human Performance." 4(4): 309-336.

Major, A.E. 2012. "Job design for special education teachers." Current Issues in Education, 
15(2). Retrieved from https://cie.asu.edu/ojs/index.php/cieatasu/article/view/900

Malinen, O., and H. Savolainen. 2016. "The effect of perceived school climate and teacher efficacy in behavior management on job satisfaction and burnout: A longitudinal study." Teaching and Teacher Education 60:144-152.

Moe, A., F. Pazzaglia, and L. Ronconi. 2010. "When being able is not enough: The combined value of positive affect and self-efficacy for job satisfaction in teaching." Teaching and Teacher Education 26(5): 1145-1153.

Myers, M. S. 1964. "Who Are Your Motivated Workers?" Harvard Business Review. Boston: Harvard Business Publishing. Retrieved from https://hbr.org/1964/01/who-areyour-motivated-workers

OECD. 2011. Lessons from PISA for the United States: Strong Performers and Successful Reformers in Education. Paris: OECD Publishing.

OECD. 2013. Teaching and learning international survey: TALIS 2013 conceptual framework. Paris: OECD Publishing.

OECD. 2014a. PISA 2012 Results: What Students Know and Can Do - Student Performance in Mathematics, Reading and Science (Volume I, Revised edition, February 2014). Paris: OECD Publishing.

OECD. 2014b. TALIS 2013 results: An international perspective on teaching and learning. Paris: OECD Publishing.

OECD. 2014c. TALIS 2013 Technical Report. Paris: OECD Publishing.

Pang, N. S. K., and Ting Wang. 2016. "Professional learning communities: Research and practices across six educational systems in the Asia-Pacific region." Asia Pacific Journal of Education 36 (2): 193-201.

Prast, E.J., E. Van de Weijer-Bergsma, E. H. Kroesbergen, and J. E. H. Van Luit. 2018. "Differentiated instruction in primary mathematics: Effects of teacher professional development on student achievement." Learning and Instruction 54: 22-34.

Reeves, P. M., W. H. Pun, and K. S. Chung. 2017. "Influence of teacher collaboration on job satisfaction and student achievement." Teaching and Teacher Education 67:227-236.

Sargent, T. C., and E. C. Hannum. 2009. "Doing more with less: Teacher professional learning communities in resource-constrained primary schools in rural china." Journal of Teacher Education 60(3):258-276.

Sellar, S., and B. Lingard. 2013. "Looking East: Shanghai, PISA 2009 and the reconstitution of reference societies in the global education policy field." Comparative Education 49(4): 464-485. 
Shen, J., J. M. Leslie, J. K. Spybrook, and X. Ma. 2012. "Are principal background and school processes related to teacher job satisfaction? A multilevel study using schools and staffing survey 2003-04." American Educational Research Journal 49(2): 200-230.

Skaalvik, E. M., and S. Skaalvik. 2010. "Teacher self-efficacy and teacher burnout: A study of relations." Teaching and Teacher Education 26(4): 1059-1069

Skaalvik, E. M., and S. Skaalvik. 2011. "Teacher job satisfaction and motivation to leave the teaching profession: Relations with school context, feeling of belonging, and emotional exhaustion." Teaching and Teacher Education 27(6): 1029-1038.

Spilt, J. M., M. Y. Koomen, and J. T. Thijs. 2011. "Teacher wellbeing: The importance of teacher student relationships.” Educational Psychology Review 23: 457-477.

Stearns, E., N. Banerjee, R. A. Mickelson, and S. Moller. 2015. "Collective Pedagogical Teacher Culture and Teacher Satisfaction.” Teachers College Record 117 (8): 1-32.

Tang, Y. P., He, W. J., Liu, L., \& Li, Q. 2018. Beyond the paycheck: Chinese rural teacher well-being and the impact of professional learning and local community engagement. Teachers and Teaching: Theory and Practice, 24(7), 825-839.

Tucker, M. 2011. Surpassing Shanghai: An agenda for American education built on the world's leading systems. Cambridge, MA: Harvard Education Press,

Tickle, B. R., M. Chang, and S. Kim. 2011. "Administrative support and its mediating effect on US public school teachers." Teaching and Teacher Education 27(2): 342-349.

Tschannen-Moran, M., and A. Woolfolk Hoy. 2001. "Teacher efficacy: Capturing an elusive construct." Teaching and Teacher Education 17: 783-805.

Van Maele, D., and M. Van Houtte. 2012. "The role of teacher and faculty trust in forming teachers' job satisfaction: Do years of experience make a difference?" Teaching and Teacher Education 28(6): 879-889.

Vieluf, S., M. Kunter, and F. J. De Vijver. 2013. "Teacher self-efficacy in cross-national perspective." Teaching and Teacher Education 35:92-103.

Wahlstrom, K., and K. S. Louis. 2008. "How teachers experience principal leadership: The roles of professional community, trust, efficacy, and shared responsibility." Educational Administration Quarterly 44(4): 458-495.

Wall, T. D., and G. M. Stephenson. 1970. "Herzberg's two-factor theory of job attitudes: A critical evaluation and some fresh evidence." Industrial Relations Journal, 1(3): 41-65.

Wang, T. 2015 . Contrived collegiality vs. genuine collegiality: Demystifying professional learning communities in Chinese Schools. Compare: A Journal of International and 
Comparative Education, 45(6), 908-930.

Wolgast, A., and N. Fischer. 2017. "You are not alone: Colleague support and goal-oriented cooperation as resources to reduce teachers' stress." Social Psychology of Education 20(1): 97-114.

Yeo, L. S., R. P. Ang, W. H. Chong, V. S. Huan, and C. L. Quek. 2008. “Teacher efficacy in the context of teaching low achieving students." Current Psychology 27(3): 192-204.

Zeggelaar, A., M. Vermeulen, and W. Jochems. 2017. "Exploring what works in professional development: an assessment of a prototype intervention and its accompanying design principles." Professional Development in Education 44(5): 1-19.

Zhou, Y. 2014. The relationship between school organizational characteristics and reliance on out-of-field teachers in mathematics and science: cross-national evidence from TALIS 2008. Asia-Pacific Education Researcher 23(3): 483-497.

\section{Article History}

Received on November 26, 2019 / Revised on January 30, 2020 / Accepted on January 31, 2020

\section{Authors}

\section{Yipeng Tang}

Associate Professor, Faculty of Education, East China Normal University, China

\section{Ting Wang}

Professor and Associate Dean (Education), Faculty of Education, University of Canberra, Australia

\section{Laura Blythe Liu}

Assistant Professor, Glocal Teacher Development Coordinator, English as a New Language Program, Indiana University-Purdue University, Columbus, USA

\section{Qiong Li}

Professor, Center for Teacher Education Research, Key Research Institute of Ministry of Education, Beijing Normal University, Beijing, China 